\title{
Arrangement of Curriculum Group for Systematic Education in Materials Science and Engineering
}

\author{
Pu Wang ${ }^{1}$, Yaoyao Yang ${ }^{2}$, Ke Wang ${ }^{2}$, Haojun Zhuo ${ }^{2}$, Deng-Guang $\mathrm{Yu}^{2, *}$ \\ ${ }^{1}$ Advanced Technical Vocational Institute, Shanghai University of Engineering Science, Shanghai 200437, China \\ ${ }^{2}$ School of Materials Science \& Engineering, University of Shanghai for Science \& Technology \\ Shanghai 200093, China
}

\begin{abstract}
In the higher education, the arrangement of curricula should give an overall consideration on the systematic cultivation on the college students' study capability, innovation capability and their innovation capability as well. In this paper, a method about the arrangement of a curriculum group for the students who major in materials science and engineering in higher grade is put forward. The curriculum group consists of several curricula, which include the professional basic courses, innovative practice course, and graduation project. The organization of these courses into a systematic group is demonstrated to be very useful for the college students to study in a systematic and coherent manner, which helps to improve their comprehensive qualities and become advanced workforce in future in the society. The suggested method in the present investigation can provide some useful hints for many other disciplines in fostering qualified labor forces for the modern society.
\end{abstract}

Keywords-Innovation education; Practice education; Systematic education; Materials science and engineering; Curriculum group

\section{INTRODUCTION}

In the traditional higher education, the focus of curriculum arrangement is on the "learning of professional knowledge" for the college students. Often, their practice capability and innovation capability are ignored to some extent. Although their study capability is good enough for them to become a qualified workforce in the modern society, they often need a relatively longer time period to adapt their working environment and meanwhile to exhibit their due performances. This is a common phenomenon reflected by many employers. Thus, it is a time to re-design the curriculum arrangement of the college lessons and the key point is how to systematically train the students' practice and innovation capabilities through the ordinary courses in a systematic manner in their colleges.

Among many natural disciplines, the field of material science and engineering (MSE) is very special one, which incorporates elements of chemistry, physics, engineering and technology as well. It is widely recognized as a distinct field of science and engineering, and major technical universities all over the world created dedicated schools of the study, within either the Science or Engineering schools. For the students who major in this discipline, the cultivation of their practice and innovation capabilities is even important for their conversions to valuable workforces in their future.

From the composition of MSE, the courses for the college students should be carefully arranged in a systematic manner.
Shown in Fig. 1, it is clear for a college student, he needs to grasp the interrelated knowledge about the preparation and processing, the characterizations on properties, structure and performances of the prepared materials [1]. The theories can be learned in the classroom. However, no matter how difficult or easy he theories about the creation or characterization of materials are, the key is that the students should have a full experience on the real materials.

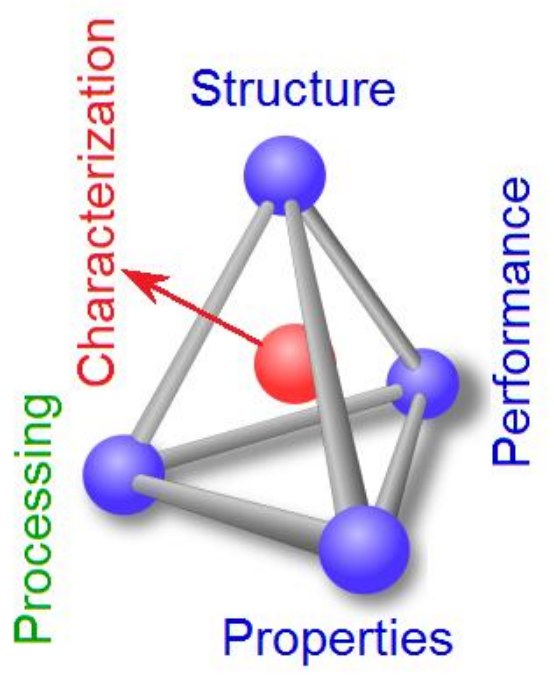

Fig. 1 The materials paradigm represented in the form of a tetrahedron [1]

Based on the above-mentioned knowledge, in the present paper, a method about the arrangement of a curriculum group for the students who major in MSE in higher grade is put forward. The curriculum group consists of a series of curricula, such as the professional basic courses, innovative practice course, and graduation project. The organization of these courses into a systematic group is expected to help to improve the students' comprehensive qualities for becoming a talent engineer in future.

\section{THE ARRANGEMENT OF CURRICULUM GROUP IN SENIOR GRADE OF COLLEGE}

In Chinese universities, the college students majoring in MSE often have four years for the pursuing their bachelor's degrees. When they are freshmen and sophomore students, all of them similarly need to study some basic courses. These cores are important for their later professional knowledge study, 
which include higher mathematics, advanced physics, advanced chemistry, and foreign language as well.

When the students have a good basic knowledge reserve during their junior years' study, then, they can begin their professional knowledge study in their later stage of their university lives, i.e. their senior period. During this stage, i.e. a period prepared to enter the society and become a valuable workforce, the integration education should be extremely important. The integration education should at least include professional practice education, innovation education and quality education as well (Fig. 2). These educations need to be implemented through the designs of different curricula, and it should be better that these curricula are arranged in a systematic and progressive manner. Some small projects about a certain functional material can be explored as the vivid teaching materials for both teaching and training them.

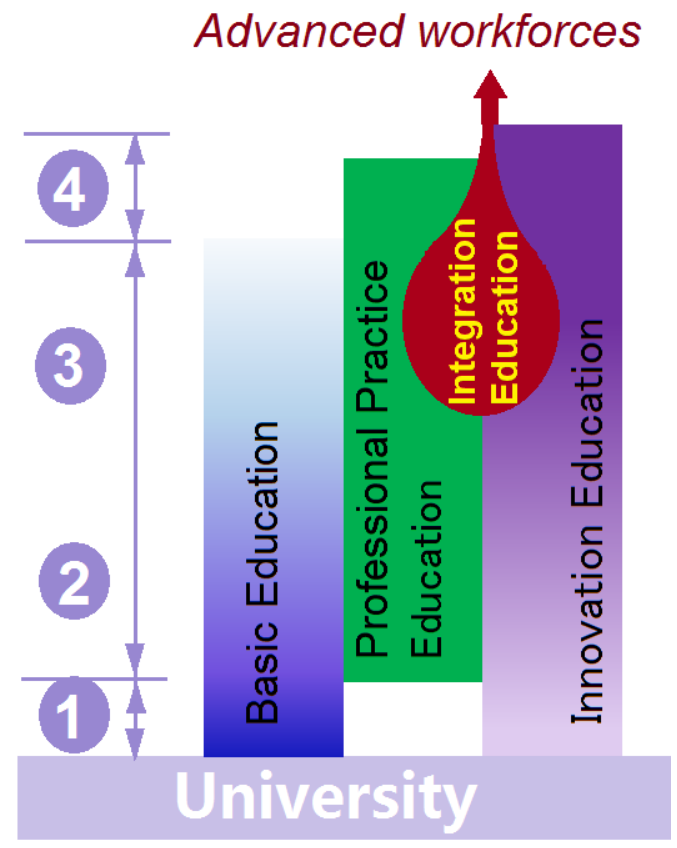

Fig. 2 An integration education is urgent for the college students in their senior grades during the university lives.

\section{THE POSSIBLE COURSES THAT CAN BE COMBINED INTO A CURRICULUM GROUP}

There are different levels of curriculum group. For example, the whole four years' college life can be arranged as a big group. In Fig. 3, a diagram shows that basic courses, professional courses and the general knowledge courses can be combined as a curriculum group for cultivating the students' comprehensive qualities.

Formerly, the college curricula are almost courses about basic courses and professional courses, ignoring the general knowledge courses to some extent. Since the Reform and Opening-up, more and more universities are conscious of the important roles of general knowledge courses in forming their students into talents for the society. Thus, courses about general competence education (including engineering \& technology, economics \& management, humanities \& social science, and culture and sports) are gradually increased in the college students' courses.

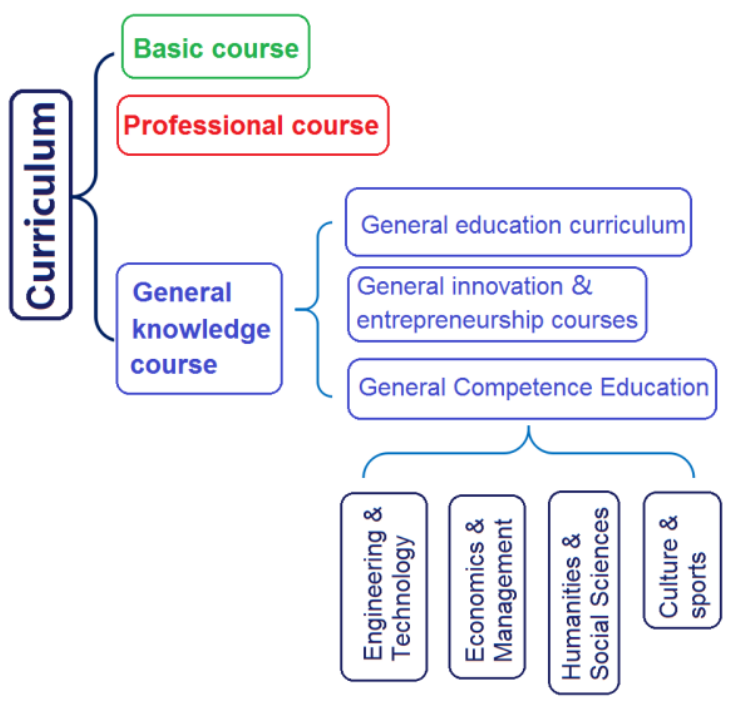

Fig. 3 Several courses can be combined into a curriculum group for cultivating the students' comprehensive qualities.

Besides the above-mentioned trend that general knowledge courses were ignored, another negative phenomenon in the college is that the students' curricula often lack enough practical training courses, particularly those on the new professional techniques. The traditional curricula are full of classroom teaching, which greatly limit the students' innovative thinking and creativity. This situation can be even worse for the college students in their senior years' study.

\section{A USEFUL CURRICULUM GROUP EXAMPLE FOR THE} SENIOR GRADE STUDENTS OF MSE

After several years' practices, here a useful curriculum group for the senior grade students of MSE to systematically improve their comprehensive capability is put forward. Shown in Fig. 4, the curriculum group is centered around a basic professional course - Modern material analysis methods. In this course, a series of knowledge about material analysis will be taught to the students, such as how to determine the materials' morphology, their inner structures, and their shapes; how to measure their components and compositions; how to evaluate the compatibility between different components; and how to verify their properties and performances.

Thus, two important questions can be clear for this course, i.e. what kinds of materials are characterized or how to prepare the materials and what are their targeted applications? The former has a close relationship with several courses about material preparation. Particularly in today nano era, the curricula about preparing nano/micro objects should be put into the group. New courses about the fabrications of nano materials should be very useful for cultivating the students' capability, these courses include the traditional chemical and physical methods [2], and also some electrohydrodynamic atomization methods [3] such as the monoaxial elecrospinning [4], monoaxial electrospraying [5], coaxial electrospinning [6], coaxial electrospraying [7] and their modified processes [8-12], 
side-by-side electrospinning [13], side-by-side electrospraying [14], tri-fluid coaxial electrospinning [15-17] and some other multiple fluid spinning or spraying processes [18].

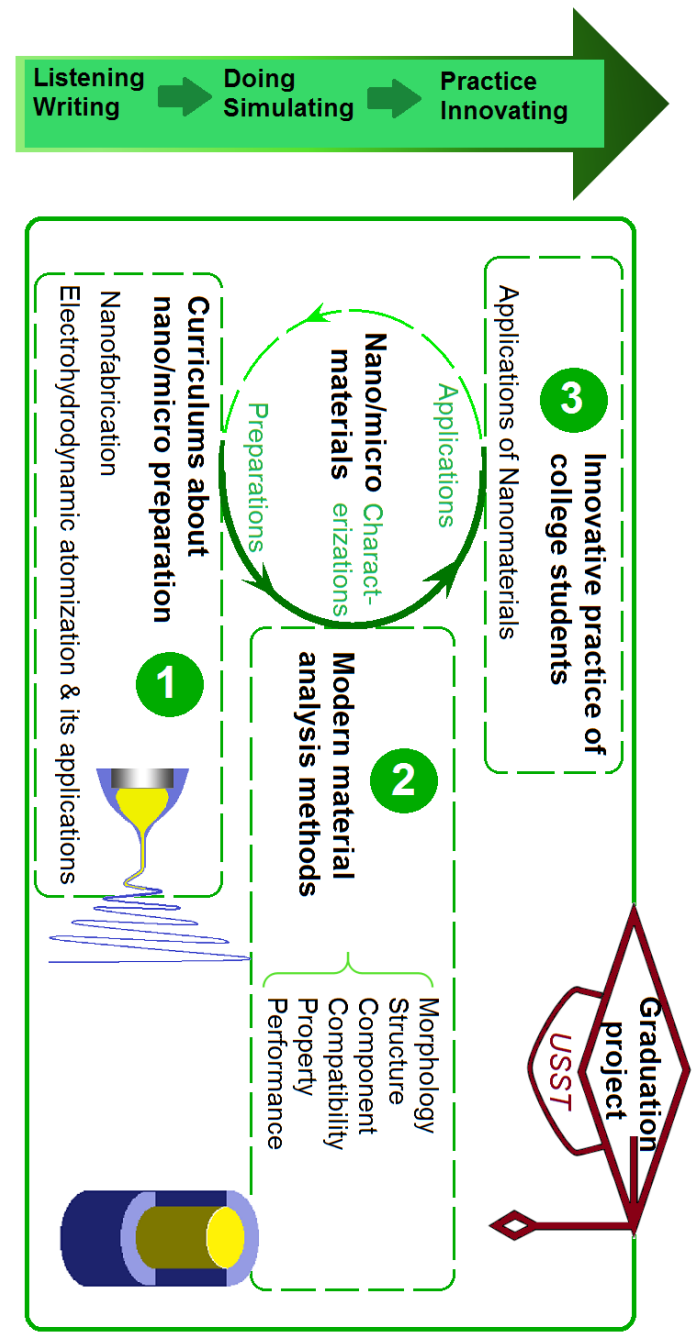

Fig. 4 An example about a useful curriculum group that is designed for the senior grade students majoring in MSE.

The latter has a close relationship with the functional applications of the created materials, particularly after a systematic characterization, their real applications should be completely included. Because there are so many kinds of different applications in this world and there are so many applied sciences, thus, a wide variety of courses about applied materials are possible to be included into this curriculum group Today, the hot topics are always about the functional performances of nanostructures. Thus, the applications of different types of structures can be taught to the students through this curriculum group. These structures include the monolithic fibers [19], monolithic particles [20], core-shell particles [21], core-sheath nanofibers [22-25], tri-layer fibers [26] and other structure combined from the core-sheath and Janus [27].

In the curriculum group, the different courses should be arranged according to a special order, for example, some courses can be imparted through listening and writing should be arranged at a relatively previous time, and some courses that must be taught through real practices can be arranged at a later time, e.g. the graduation project is often arranged at the final semester of the students' college life.

\section{SUMMARY}

Being as the universities for cultivating the talents, it is very important to cultivate large number of the innovative talents with the innovative spirit and the practice ability. Deepening innovation and entrepreneurship education are the main direction of current teaching reform in colleges and universities. The course reform should be one of the most important section within the teaching reform. The present strategy for arranging a curriculum group to carry out a systematic education about MSE can provide a useful bridge to connect their present discrete basic courses and professional courses with their final graduation project. The curriculum group can also act as an upward step for the students from simulating to practice in an innovative manner. Certainly, the present curriculum group shows an example for other disciplines about natural science and engineering to reform their teaching procedures or methods.

\section{REFERENCES}

[1] https://en.wikipedia.org/wiki/Materials_science, 2018-11-11

[2] D.G. Yu, J.J. Li, G.R. Williams, and M. Zhao, "Electrospun amorphous solid dispersions of poorly water-soluble drugs: A review," J. Control. Release, vol. 292, pp.91-110, 2018.

[3] T. Hai, X. Wan, D.G. Yu, K. Wang, Y. Yang, Z.P. Liu, "Electrospun lipid-coated medicated nanocomposites for an improved drug sustainedrelease profile," Mater. Design, vol.162, pp.70-79, 2019.

[4] Z. Zhang, W. Li, G. Wang, Y.L. Qu, and D.G. Yu, "Electrospun 4th generation solid dispersions of poorly water-soluble drug utilizing two different processes," J. Nanomater. vol.2018, no.2012140, 2018.

[5] X.Y. Li, Z.B. Zheng, D.G. Yu, X.K. Liu, Y.L. Qu, and H.L. Li, "Electrosprayed sperical ethylcellulose nanoparticles for an improved sustained-release profile of anticancer drug," Cellulose, vol.24, pp.55515564, 2017

[6] Y.H. Wu, D.G. Yu, H.P. Li, X.Y. Wu, and X.Y. Li, "Medicated structural PVP/PEG composites fabricated using coaxial electrospinning," e-Polymers, vol.17, pp.39-44, 2017.

[7] Y.Y. Yang, M. Zhang, Z.P. Liu, K. Wang, and D.G. Yu, "Meletin sustained-release gliadin nanoparticles prepared via solvent surface modification on blending electrospraying," App. Surf. Sci., vol.434, pp.1040-1047, 2018.

[8] Q. Wang, D.G. Yu, L.L. Zhang, X.K. Liu, Y.C. Deng, and M. Zhao, "Electrospun hypromellose-based hydrophilic composites for rapid dissolution of poorly water-soluble drug," Carbohydr. Polym., vol.174, pp.617-625, 2017

[9] H. Zhou, Z. Shi, X. Wan, H. Fang, D.-G. Yu, X. Chen, P. Liu, "The relationships between process parameters and polymeric nanofibers fabricated using a modified coaxial electrospinning," Nanomaterials, vol.9, no.843, 2019

[10] W. Huang, Y. Yang, B. Zhao, G. Liang, S. Liu, X.-L. Liu, and D.G. Yu, "Fast dissolving of ferulic acid via electrospun ternary amorphous composites produced by a coaxial process," Pharmaceutics, vol.10, no. 115,2018

[11] D.G. Yu, X. L. Zheng, Y. Yang, X. Y. Li, G.R. Williams, M. Zhao, "Immediate release of helicid from nanoparticles produced by modified coaxial electrospraying," Appl. Surf. Sci., vol.473, pp.148-155, 2019.

[12] X. Liu, W. Shao, M. Luo, J. Bian, D.G. Yu, "Electrospun blank nanocoating for improved sustained release profiles from medicated gliadin nanofibers," Nanomaterials, vol.8, no.184, 2018. 
[13] Y.Y. Yang, M. Zhang, K. Wang, and D.G. Yu, "pH-sensitive polymer nanocoating on hydrophilic composites fabricated using modified coaxial electrospraying,” Mater. Lett., vol.227, pp.93-96, 2018.

[14] K. Wang, X.K. Liu, X.H. Chen, D.G. Yu, Y.Y. Yang, and P. Liu, "Electrospun hydrophilic Janus nanocomposites for the rapid onset of therapeutic action of helicid," ACS Appl. Mater. Interfaces, vol.10, pp.2859-2867, 2018

[15] M. Wang, T. Hai, Z. Feng, D.-G. Yu, Y. Yang, S.W. Annie Bligh, "The relationships between the working fluids, process characteristics and products from the modified coaxial electrospining of zein," Polymers, vol.11, no.1287, 2019.

[16] Z.P. Liu, Y.Y. Zhang, D.G. Yu, D. Wu, and H.L. Li, "Fabrication of sustained-release zein nanoparticles via modified coaxial electrospraying," Chem. Eng. J., vol.334, pp.807-816, 2018.

[17] Y. Xu, J.J. Li, D.G. Yu, G.R. Williams, J.H. Yang, and X. Wang, "Influence of the drug distribution in electrospun gliadin fibers on drugrelease behavior,” Eur. J. Pharm. Sci., vol.106, pp.422-430, 2017.

[18] W. Huang, Y. Hou, X. Lu, Z. Gong, Y. Yang, X.-J. Lu, X.-L. Liu, D.G. $\mathrm{Yu}$, "The process-property-performance relationship of medicated nanoparticles prepared by modified coaxial electrospraying," Pharmaceutics, vol.11, no.226, 2019.

[19] Y. Yang, T. Zhu, Z. Liu, M. Luo, D.-G. Yu, S.W. Annie Bligh, “The key role of straight fluid jet in predicting the drug dissolution from electrospun nanofibers," Int. J. Pharm., vol.569, nol.118634, 2019.

[20] Z.P. Liu, L.L. Zhang, Y.Y. Yang, D. Wu, G. Jiang, and D.G. Yu, "Preparing composite nanoparticles for immediate drug release by modifying electrohydrodynamic interfaces during electrospraying," Powder Technol., vol.327, pp.179-187, 2018.

[21] K. Wang, H.F. Wen, D.G. Yu, Y. Yang, and D.F. Zhang, "Electrosprayed hydrophilic nanocomposites coated with shellac for colon-specific delayed drug delivery," Mater. Design, vol.143, pp.248$255,2018$.

[22] Y.Y. Yang, Z.P. Liu, D.G. Yu, K. Wang, P. Liu, X. Chen, "Colonspecific pulsatile drug release provided by electrospun shellac nanocoating on hydrophilic amorphous composites," Int. J. Nanomed. vol.2018, pp. 2395-2404, 2018.

[23] J.J. Li, Y.Y. Yang, D.G. Yu, Q. Du, X.L. Yang, "Fast dissolving drug delivery membrane based on the ultra-thin shell of electrospun core-shell nanofibers," Eur. J. Pharm. Sci., vol.107, pp.195-204, 2018.

[24] Q. Wang, D.G. Yu, S.Y. Zhou, C. Li, and M. Zhao, "Fabrication of amorphous electrospun medicated-nanocomposites using a Teflon-based concentric spinneret," e-Polymer, vol.18, pp.3-11, 2018.

[25] X. Liu, Y. Yang, D.G. Yu, M.J. Zhu, M. Zhao, G.R. Williams, "Tunable zero-order drug delivery systems created by modified triaxial electrospinning," Chem. Eng. J., vol. 356, pp.886-694, 2019.

[26] Y. Yang, W. Li, D.G. Yu, G. Wang, G.R. Williams, Z. Zhang, "Tunable drug release from nanofibers coated with blank cellulose acetate layers fabricated using tri-axial electrospinning," Carbohydr. Polym., vol.203, pp.228-237, 2019

[27] D.G. Yu, J.J. Li, M. Zhang, and G.R. Williams, "High-quality Janus nanofibers prepared using three-fluid electrospinning," Chem. Commun. vol.53, pp.4542-4545, 2017 